\title{
Social contexts and the occurrence of episodic heavy drinking
}

\author{
Daniela Piontek $^{1}$, Ludwig Kraus ${ }^{1,2}$, and Fred Rist ${ }^{3}$ \\ ${ }^{1}$ IFT Institut für Therapieforschung, Munich, Germany \\ ${ }^{2}$ Centre for Social Research on Alcohol and Drugs, SoRAD, Stockholm University, Stockholm, Sweden \\ ${ }^{3}$ Klinische Psychologie und Psychotherapie, Institut für Psychologie, Westfälische Wilhelms-Universität Münster, Münster, Germany
}

\begin{abstract}
Aims: This study aims to investigate the influence of social context variables on Episodic Heavy Drinking (EHD) among young adults. It will assess (a) whether EHD is predicted by characteristics of the specific drinking situation and drinking motives, and (b) whether the influence of drinking motives is moderated by public versus private drinking.

Design/Setting: Data were collected by means of an online survey conducted at the University of Münster (Germany) in December 2008.

Participants: The analytical sample consisted of 1,638 students.

Instruments: Information was collected on socio-demographics, habitual drinking behavior (beverage-specific quantity and frequency within the past 30 days, EHD, drunkenness), and drinking motives (Drinking Motive Questionnaire Revised, DMQ-R). Moreover, participants described a recent drinking situation (beverage-specific quantity, drunkenness) as well as the social context related to this situation (time, place, people present, other substances used). Multivariate regression analyses were used to test the influence of context variables and their interaction with drinking motives.
\end{abstract}

Findings: Drinking at a birthday or special party, during the weekend, or in a group where many people were drunk and playing drinking games increased the risk of EHD. Social and enhancement motives were associated with a higher risk for EHD, whereas conformity motives had a protective effect on heavy drinking. The effect of conformity motives was only present in public drinking situations.

Conclusions: Drinking in young people is a social phenomenon related to situational influences as well as individual characteristics. In addition, there seems to be situational moderation of the impact of specific drinking motives.

Alcohol consumption is related to the social context in which it occurs; that is, factors such as where, when, with whom and why one drinks affect the amount of alcohol that is consumed. It has been argued that different contexts construct normative frameworks that define whether drinking is considered an appropriate behavior or not (Greenfield \& Room, 1997; Klein \& Pittman, 1990; Lo Monaco, Piermattéo, Guimelli, \& Ernst-Vintila, 2011). Accordingly, social drinking promotes a norm that is permissive of drinking and even drunkenness. Public locations away from home, such as parties, bars or discos, are strongly related to heavy drinking (Demers et al., 2002; Forsyth \& Barnard, 2000). Especially within student populations, parties are common social events and were reported to be the most common circumstance for drinking large amounts of alcohol (Clapp, Shillington, \& Segars, 2000; Harford, Wechsler, \& Seibring, 2002).
When and with whom one drinks also affects alcohol consumption. For example, Demers and colleagues (2002) found that heavy drinking occurs more often on weekends and in large groups. Activities of social groups are often centered on drinking alcohol, and drunkenness is sought as a goal, which influences the type of alcohol consumed and encourages phenomena such as pre-gaming (Lange, DevosComby, Moore, Daniel, \& Homer, 2011). The presence of peers or underage strangers seems to increase the risk of drinking large amounts, unlike the presence of family members or other adults (Demers et al., 2002; Mayer, Forster, Murray, \& Wagenaar, 1998). Consuming alcohol in a public location and together with friends may also increase the likelihood of being in the company of intoxicated people (Clapp \& Shillington, 2001; Forsyth \& Barnard, 2000). 
Most young people drink alcohol for social reasons, such as social facilitation or for enjoyment (Knibbe, van de Goor, \& Drop, 1993; Kuntsche, Knibbe, Gmel, \& Engels, 2005). Other motives include drinking to fit in with a group and drinking to cope with problems. In general, both enhancement and coping motives are strongly endorsed by heavy drinkers (Kairouz, Gliksman, Demers, \& Adlaf, 2002; Kassel, Jackson, \& Unrod, 2000; Labouvie \& Bates, 2002). However, there is evidence that drinking motives and social contexts are not independent (Kuntsche, Knibbe, Gmel, \& Engels, 2006a). Enhancement and social drinking reasons are more closely related to drinking in social situations, and tend to increase the risk of consuming heavily and of experiencing negative consequences (Cooper, Russell, Skinner, \& Windle, 1992; Cooper, Agocha, \& Sheldon, 2000; Gonzales, Collins, \& Bradizza, 2009). In contrast, coping motives are strongly associated with solitary drinking (Cooper et al., 1992; Gonzales et al., 2009).

In contrast to many other countries, where college students are a major focus of scientific research, in Germany there is hardly any information available concerning this population's alcohol use behavior. Preliminary results suggest that problematic alcohol use is more prevalent among university students than in the general population (Bailer et al., 2009). The present study builds upon previous research by examining whether specific social context variables are associated with the occurrence of Episodic Heavy Drinking (EHD) in German university students. It is hypothesized (1) that the occurrence of EHD is independently predicted both by social context variables related to the specific drinking situation and by drinking motives; and (2) that the influence of drinking motives is moderated by public versus private drinking. Specifically, it is assumed that social and enhancement motives predict EHD in public situations, whereas coping motives predict heavy drinking in private locations.

\section{Methods}

\section{Sample}

Data were collected by means of an online survey conducted at the University of Münster in December 2008. A random sample of 10,000 e-mail addresses was drawn from the total student population $(N=37,086)$. An e-mail was sent to the selected students including information about the purpose and content of the survey as well as an external link to the online questionnaire. Respondents were informed that participation was voluntary and that all information would be kept completely anonymous. Out of the 10,000 eligible students, 2,547 participated in the survey, resulting in an initial response rate of $25.5 \%$. Participants were excluded if they had dropped out of the survey before completion ( $n=585,23.0 \%$ ), did not give their informed consent $(n=15,0.5 \%)$, responded repeatedly ( $n=32,5.2 \%$ ), indicated that they were not students at the University of Münster ( $n=27,1.1 \%)$ or were not within the age range 18 to $29(n=66,2.6 \%)$. The final analytical sample comprised 1,722 students (17.2\%).

\section{Measures}

\section{Drinking situations}

In order to obtain information on drinking situations with and without EHD, the survey was split. Half of the participants were asked to remember the last occasion at which they drank five or more glasses of alcohol (5+ survey), whereas the other half was asked to remember the last occasion at which they drank a maximum of four glasses of alcohol (4- survey). Based on the reported quantity of alcohol, however, it emerged that there were respondents in the 5+ survey who had described an occasion with less than five drinks, and vice versa. Thus, the final differentiation between EHD situations and nonEHD situations was based on this quantity measure. Sensitivity analyses comparing the habitual drinking behavior of those who answered in accordance with the instructions and those who answered in conflict with the instructions supported this decision. Drinking frequency, average quantity of alcohol consumed, and frequency of EHD was comparable for students reporting at least five drinks, irrespective of whether they correctly answered the $5+$ survey or should have answered the 4 - survey. The same was true for the respondents reporting four or less drinks.

\section{Socio-demographics}

Age and gender were considered as socio-demographic characteristics. The length of the studies was assessed as the total number of semesters.

\section{Habitual drinking behavior}

Habitual drinking behavior, based on the past 30 days, was assessed on a beverage-specific quantity frequency index: (1) "On how many days within the past 30 days did you drink alcohol?" and (2) "Within the past 30 days, which of the following beverages did you drink on an average day when you drank alcohol (indicate number of glasses): beer, wine/champagne, spirits, alcopops?” The meaning of a glass was defined by giving container sizes for different beverages reflecting equivalent ethanol contents (approx. 12 grams). Average daily alcohol intake in grams of ethanol was calculated using beverage-specific standard ethanol contents (Bühringer et al., 2002). Frequency of episodic heavy drinking was assessed by asking, "Within the past 30 days, on how many days did you drink five or more glasses of alcohol on a single occasion?” Thus, an EHD situation was defined as drinking an equivalent of approximately 60 grams of ethanol. With regard to the specific drinking situation, alcohol intake in grams of ethanol, the total number of drinks, and the subjective feeling of drunkenness $(1=$ "not at all drunk" to $10=$ “heavily drunk”) was assessed.

\section{Context characteristics}

Context characteristics of the drinking situations were measured by eight indicators. For the specific drinking situation they were asked to remember, respondents indicated the location where drinking occurred (private [e.g., at home] or public [e.g., at a bar, restaurant or concert]), the reason for drinking (birthday, passed examination, special holiday [e.g., Halloween], special party [e.g., matriculation or fraternity party], or no 
particular reason), the day of the week (weekday [i.e., Monday to Thursday] or weekend [i.e., Friday to Sunday]), whether fellow students and/or friends were present (yes or no), whether the respondent's partner and/or family members were present (yes or no), the total number of other people present, the estimated percentage of people who were drunk, and whether the respondent participated in drinking games (yes or no).

\section{Drinking motives}

Drinking motives were assessed using the Drinking Motive Questionnaire Revised (DMQ-R) (Cooper, 1994; Kuntsche, Stewart, \& Cooper, 2008). Respondents indicated how often they usually drink alcohol for a total of 20 reasons, using a six-point scale ranging from "never" to "almost always." In the original version, the DMQ-R consists of four subscales (enhancement, social, conformity, and coping). In the present sample, an exploratory factor analysis yielded three dimensions. The first factor (eigenvalue 9.05, Cronbach's alpha 0.91) covered nine items assessing enhancement and social drinking motives (e.g., "because it improves parties and celebrations"). The second factor (eigenvalue 3.02, Cronbach's alpha 0.89) comprised four items reflecting coping motives (e.g., "to forget your worries”). The third factor (eigenvalue 1.97, Cronbach's alpha 0.80) included seven items mainly assessing conformity motives (e.g., "so that others won't kid you about not drinking”).

\section{Statistical analyses}

The drinking occasions described by the respondents were divided into EHD situations $(n=625)$ and non-EHD situations $(n=1,013)$. Bivariate comparisons with regard to alcohol consumption and context variables were made using Pearson Chi square tests for dichotomous variables and Wilcoxon two-sample tests for continuous variables. In order to assess the relationship between EHD/non-EHD situations and context variables, logistic regression analyses were used. The context indicators, the three dimensions of drinking motives, and the interaction effects between drinking location (private or public) and drinking motives were included as predictors. Analyses were controlled for socio-demographic characteristics and habitual drinking behavior. Due to the fact that the alcohol consumption indicators were skewed towards lighter consumption, these variables were square root transformed in order to approximate a normal distribution. Odds Ratios $(O R)$ and 95\% confidence intervals are reported. For a graphical display of significant interaction effects, predicted probabilities for each level of the predictor "location" were calculated and plotted against the whole range of the particular drinking motive dimension. Analyses were conducted using the Stata 12.0 SE software package (Stata Corp LP, College Station, TX).

\section{Results}

\section{Sample description}

Study participants were on average 23.45 years old; about $51 \%$ were females (Table 1). Average length of studies was 7.03 semesters. Within the previous 30 days, students had drunk alcohol on approximately seven days, with an average daily alcohol intake of 14.24 grams of ethanol. Episodic heavy drinking took place on 2.64 days. Enhancement/social drinking motives were more strongly endorsed than conformity and coping motives.

The characteristics of the specific drinking situations described by the respondents are summarised in Table 2 . Alcohol volume, number of drinks, and degree of drunkenness were higher in EHD than in non-EHD situations. Drinking occasions involving EHD were more often related to birthday or special parties, occurred more often on weekends, involved more people, were accompanied by higher degrees of drunkenness, and occurred more frequently in the presence of fellow students or friends and when drinking games were played.

Table 1

Socio-demographic and drinking characteristics of the sample

\begin{tabular}{lc}
\hline & Student sample $\boldsymbol{n}=\mathbf{1 , 7 2 2}$ \\
\hline Socio-demographic characteristics & \\
Age, $M(S D)$ & $23.45(2.28)$ \\
Females, $n(\%)$ & $883(51.30)$ \\
Number of semesters, $M(S D)$ & $7.03(3.67)$ \\
Habitual drinking behavior (30 days) & \\
Drinking frequency, $M(S D)$ & $7.15(5.36)$ \\
Average daily alcohol intake, $M(S D)$ & $14.24(17.74)$ \\
EHD frequency, $M(S D)$ & $2.64(3.42)$ \\
Drinking motives, $M(S D)$ & \\
Social/enhancement & $2.91(1.04)$ \\
Conformity & $1.43(0.53)$ \\
Coping & $1.57(0.79)$ \\
\hline
\end{tabular}

EHD = episodic heavy drinking, $M=$ mean, $S D$ = standard deviation. 
Table 2

Alcohol consumption and social contexts related to the specific drinking situation

\begin{tabular}{|c|c|c|c|}
\hline & Non-EHD $n=1,013$ & EHD $n=625$ & Sign \\
\hline \multicolumn{4}{|l|}{ Alcohol consumption } \\
\hline Alcohol volume in grams, $M(S D)$ & $40.02(19.76)$ & $104.25(55.56)$ & $* * *$ \\
\hline Number of drinks, $M(S D)$ & $2.77(1.16)$ & $8.84(5.73)$ & $* * *$ \\
\hline Subjective drunkenness, $M(S D)$ & $2.63(1.58)$ & $5.31(1.94)$ & $* * *$ \\
\hline \multicolumn{4}{|l|}{ Context characteristics } \\
\hline Drinking location, $n(\%)$ & & & ns \\
\hline Public & $385(38.01)$ & $252(40.32)$ & \\
\hline Private & 628 (61.99) & $373(59.68)$ & \\
\hline Drinking reason, $n(\%)$ & & & $* * *$ \\
\hline Birthday & $131(12.93)$ & $114(18.24)$ & \\
\hline Passed examination & $66(6.52)$ & $53(8.48)$ & \\
\hline Special holiday & $52(5.13)$ & $22(3.52)$ & \\
\hline Special party & $271(26.75)$ & $273(43.68)$ & \\
\hline No particular reason & $493(48.67)$ & $163(26.08)$ & \\
\hline Weekday, $n(\%)$ & & & $* * *$ \\
\hline Weekday (Monday to Thursday) & $428(42.25)$ & $175(28.00)$ & \\
\hline Weekend (Friday to Sunday) & $585(57.75)$ & $450(72.00)$ & \\
\hline \multicolumn{4}{|l|}{ Other people present, $n$ (\%) } \\
\hline Fellow students, friends & 875 (86.38) & $609(97.44)$ & $* * *$ \\
\hline Partner, family members & $375(37.02)$ & $234(37.44)$ & ns \\
\hline Number of other people present, $M(S D)$ & $8.68(14.21)$ & $14.53(21.57)$ & $* * *$ \\
\hline Percentage of drunken people, $M(S D)$ & $21.38(25.42)$ & $52.38(29.96)$ & $* * *$ \\
\hline Drinking games, $n(\%)$ & 20 (1.97) & $61(9.76)$ & $* * *$ \\
\hline
\end{tabular}

EHD = episodic heavy drinking, $M=$ mean, $S D=$ standard deviation. ${ }^{* * *} p<.001, n s=$ not significant

\section{Regression analyses}

When controlling for habitual drinking behavior and alcohol volume consumed at the specific occasion, several context variables predicted the occurrence of EHD (Table 3). The risk of reporting an EHD drinking situation was increased when drinking was related to a birthday or a special party, when it occurred on a weekend, when a high percentage of persons present was drunk and when drinking games were played. Moreover, two main effects emerged with regard to drinking motives: EHD was more likely in respondents holding stronger social/enhancement motives and less likely in students characterised by stronger conformity motives.

The effect of conformity motives on the occurrence of EHD occasions was moderated by drinking location. Figure 1 shows that conformity motives decreased the probability for EHD more strongly in public drinking situations than in private drinking situations. When the endorsement of conformity motives was very low, the probability of EHD was higher in public than in private situations, whereas the opposite was true when conformity motives were more strongly endorsed.

\section{Discussion}

To our knowledge, this is the first study to assess social context predictors of episodic heavy drinking (EHD) in German college students. The population of young people at universities has often been characterised as showing a "wet" drinking culture, permissive to heavy drinking (Bailer et al., 2009; Harford et al., 2002). Identification of risk factors associated with problematic drinking patterns could be helpful in deducing meaningful prevention and early intervention measures.

Several characteristics of the specific drinking situation had an influence on whether the occasion resulted in EHD or not. These include drinking at a birthday or special party, during the weekend, or in a group where many people were drunk, as well as playing drinking games. These aspects have also been identified as predisposing factors for heavy drinking in university students in other countries (Clapp et al., 2000; Demers et al., 2002; Harford et al., 2002; Kairouz et al., 2002). In accordance with the results of these earlier studies, the present findings show that drinking in young people is a social phenomenon related to external influences in addition to individual characteristics. 
Table 3

Results of logistic regression analyses to predict EHD vs. non-EHD situations $(n=1,626)$

\begin{tabular}{|c|c|c|c|}
\hline & Odds Ratio & $95 \%$ CI & Sign. \\
\hline Sex & 1.00 & $0.68 ; 1.48$ & $n s$ \\
\hline Age & 1.00 & $0.89 ; 1.12$ & $n s$ \\
\hline Number of semesters & 0.91 & $0.85 ; 0.98$ & $* * *$ \\
\hline EHD frequency (30 days) & 1.11 & $0.84 ; 1.45$ & ns \\
\hline Drinking frequency (30 days) & 0.81 & $0.70 ; 0.99$ & $*$ \\
\hline Average daily alcohol intake & 4.01 & $3.41 ; 4.72$ & $* * *$ \\
\hline Drinking location (public) & 0.58 & $0.15 ; 2.27$ & $n s$ \\
\hline \multicolumn{4}{|l|}{ Drinking reason } \\
\hline Birthday & 3.32 & $1.89 ; 5.83$ & $* * *$ \\
\hline Passed examination & 0.99 & $0.47 ; 2.07$ & $n s$ \\
\hline Special holiday & 0.96 & $0.30 ; 3.02$ & $n s$ \\
\hline Special party & 2.06 & $1.31 ; 3.23$ & $* *$ \\
\hline Weekday (weekend) & 2.15 & $1.46 ; 3.16$ & $* * *$ \\
\hline Presence of fellow students, friends & 1.50 & $0.61 ; 3.68$ & $n s$ \\
\hline Presence of partner, family members & 0.81 & $0.55 ; 1.20$ & $n s$ \\
\hline Number of other people present & 1.00 & $0.98 ; 1.01$ & $n s$ \\
\hline Percentage of drunken people & 1.02 & $1.01,1.02$ & $* * *$ \\
\hline Drinking games & 4.91 & $1.99 ; 12.13$ & $* * *$ \\
\hline Social/enhancement motives & 1.78 & $1.20 ; 2.64$ & $* *$ \\
\hline Conformity motives & 0.36 & $0.18 ; 0.72$ & $* *$ \\
\hline Coping motives & 0.78 & $0.51 ; 1.18$ & $n s$ \\
\hline Drinking location*Social/enhancement motives & 0.65 & $0.40 ; 1.05$ & $n s$ \\
\hline Drinking location*Conformity motives & 2.43 & $1.04 ; 5.69$ & $*$ \\
\hline Drinking location*Coping motives & 1.21 & $0.70 ; 2.09$ & ns \\
\hline
\end{tabular}

EHD = episodic heavy drinking. $\mathrm{CI}=$ confidence interval.

${ }^{*} p<.05 . * * p<.01 .{ }^{* * *} p<.001, n s=$ not significant.

Surprisingly, we did not find a significant effect of the size and composition of the drinking group. In a multilevel study, Demers and colleagues (2002) also found no effect of the presence of a regular partner on alcohol intake. The authors concluded that this might have been due to the fact that in a student population, the partner is likely a student too, sharing the same drinking norms as the respondent. However, this and other studies emphasized the peer group as important social influence. The absence of an effect of the partner relationship may be a result of the strong impact of the other included variables that might already explain much of the variance in the presence of peers. Looking beyond the size and composition of the drinking group, Lange and colleagues (2011) described different social roles within collegiate natural drinking groups. These roles were related to the organisation of the gathering, drinking activities, social regulation and pro-social behavior. The specific role an individual takes on in the group may influence his or her drinking behavior; for example, the designated driver or caregiver will abstain from alcohol, or at least not drink to excess.

A major contribution of the present study is the finding that after controlling for other situational influences, drinking motives independently predict episodic heavy drinking. Individuals who typically drink to obtain positive outcomes (social/enhancement) are at higher risk for heavy drinking; those who drink to avoid negative outcomes (conformity) are at lower risk. Social and enhancement motives are linked to the expectation that drinking will result in having a lot of fun and being more friendly and outgoing. According to Greenfield and Room (1997), such "wet" situations, in which drinking is seen as pro-normative, are conducive to heavier drinking. In contrast, conformity motives are stimulated by negative external influences (e.g., group pressure) and tend to result in less extensive drinking.

It is interesting to note that the separation of social and enhancement motives that has been emphasized by Kuntsche, Knibbe, Gmel, and Engels (2006b) could not be replicated in our sample; items assessing these dimensions loaded on a single factor. This might be due to differences between the study populations, as the earlier study examined adolescent instead of young adult samples. In individuals who have started to drink at a young age, social drinking motives might be more differentiated; when they grow older this may cease to be the case. 


\section{Figure 1}

Interaction effect of drinking location and conformity motives in the prediction of EHD situations

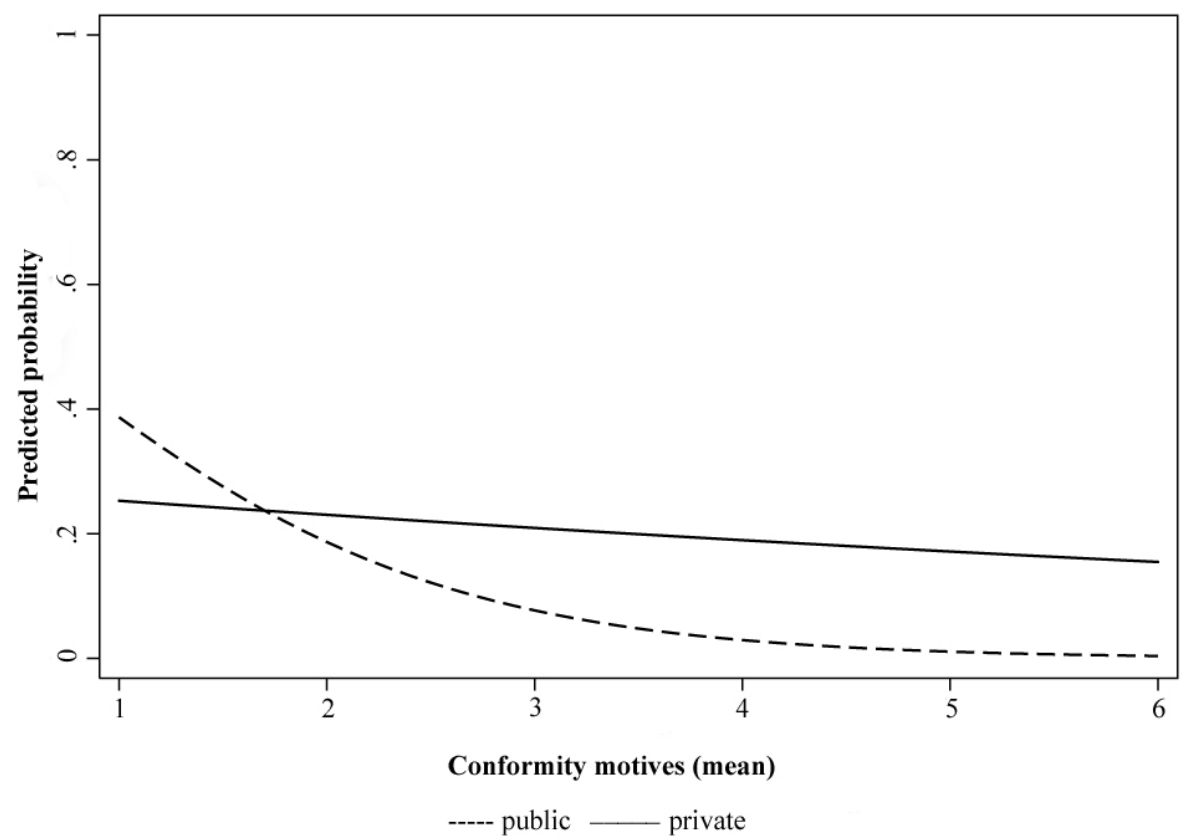

Contrary to our hypothesis, we did not find a significant association between coping motives and EHD. This seems to contradict previous research (Cooper et al., 2000; Kassel et al., 2000; Labouvie \& Bates, 2002). However, there is evidence that there may be differences depending on whether drinking motives are assessed as stable individual characteristics or as context-specific characteristics (Mihic, Wells, Graham, Tremblay, \& Demers, 2009). It might be possible that drinking to cope is only associated with a specific EHD situation when it is assessed as a situational motive and not as a person-level motive. In contrast, when drinking motives are measured as general traits, as in our study, they may be related to more general drinking habits, such as frequency of episodic heavy drinking.

Our hypotheses with regard to a moderation effect of drinking location on social/enhancement and coping motives could not be confirmed. This might be due to the measure of drinking location used in our study. A private drinking situation was described with the label "e.g., at home," which does not necessarily mean that drinking occurred in the absence of others. Birthday and other parties are often conducted at home, which, in particular, might blur the differences between private and public drinking locations.

In contrast to other motive dimensions, drinking to avoid social rejection has not been studied extensively (Kuntsche et al., 2005). In our student sample, conformity motives had a protective effect on heavy drinking. However, our analyses revealed that this negative relationship was stronger in public drinking situations. It could be assumed that the motivation to conform to the drinking behavior of others depends on the individual's personal relationship to the members of the drinking group. In private settings, drinking companions will more likely be close friends and/or family members. When this group puts pressure on an individual to drink, he or she will more likely increase his or her drinking rate in order not to affront the others. When, in contrast, group pressure comes from less close friends and/or strangers in public drinking situations, there might be less motivation to conform.

\section{Limitations of the Present Study}

The results of the present study need to be discussed in the light of several limitations. First, the survey instruction to describe either a 5+ or a 4- drinking situation did not work, and EHD and non-EHD situations had to be separated ex post. Our sensitivity analyses showed that respondents answering in conflict with the instruction tended to describe a typical drinking situation, reflecting their habitual drinking behavior. Research in cognitive psychology suggests that this may be due to a mental shortcut called availability heuristic; individuals find it easier to recall events that are relatively more common and occur more frequently (Schwarz et al., 1991; Tversky \& Kahneman, 1973). When the analyses were repeated using only data from those respondents who had answered correctly, the results remained the same. Second, given the fact that our study used drinking occasions as the unit of analysis and focused on the characteristics of these occasions, we could not consider individual characteristics beyond drinking motives and demographic characteristics. Multilevel 
studies assessing different drinking situations of different individuals are needed to jointly address both aspects. Third, the cross-sectional data structure does not allow causal interpretations, in the sense that specific drinking contexts cannot be said to lead to EHD. The reported association between context and consumption might also be an artefact of the self-selection processes-that is, heavy drinkers might be more likely to choose heavy drinking situations.

\section{Conclusions}

In conclusion, our study showed that specific social context variables are associated with the occurrence of episodic heavy drinking in German university students. Conformity motives seem to be differentially related to heavy drinking, depending on the situation. Future studies should examine more closely the situational variation of drinking motives and whether they should be considered stable personal characteristics (traits) or context-specific states.

\section{References}

Bailer, J., Stübinger, C., Dressing, H., Gass, P., Rist, F., \& Kühner, C. (2009). Zur erhöhten Prävalenz des problematischen Alkoholkonsums bei Studierenden [Increased prevalence of problematic alcohol consumption in university students). Psychotherapie Psychosomatik Medizinische Psychologie, 59, 376379.

Bühringer, G., Augustin, R., Bergmann, E., Bloomfield, K., Funk, W., Junge, B., . . . Töppich, J. (2002). Alcohol consumption and alcohol-related problems in Germany. Göttingen, Germany: Hogrefe \& Huber Publishing.

Clapp, J. D., \& Shillington, A. M. (2001). Environmental predictors of heavy episodic drinking. The American Journal of Drug and Alcohol Abuse, 27, 301-313.

Clapp, J. D., Shillington, A. M., \& Segars, L. B. (2000). Deconstructing contexts of binge drinking among college students. The American Journal of Drug and Alcohol Abuse, 26, 139-154.

Cooper, M. L. (1994). Motivations for alcohol use among adolescents: Development and validation of a fourfactor model. Psychological Assessment, 6, 117-128.

Cooper, M. L., Agocha, V. B., \& Sheldon, M. S. (2000). A motivational perspective on risky behaviors: The role of personality and affect regulatory processes. Journal of Personality, 68, 1059-1088.

Cooper, M. L., Russell, M., Skinner, J. B., \& Windle, M. (1992). Development and validation of a threedimensional measure of drinking motives. Psychological Assessment, 4, 123-132.

Demers, A., Kairouz, S., Adlaf, E. M., Gliksman, L., Newton-Taylor, B., \& Marchand, A. (2002). Multilevel analysis of situational drinking among Canadian undergraduates. Social Science \& Medicine, 55, 415-424.

Forsyth, A., \& Barnard, M. (2000). Preferred drinking locations of Scottish adolescents. Health \& Place, 6, 105-115.
Gonzalez, V. M., Collins, R. L., \& Bradizza, C. M. (2009). Solitary and social heavy drinking, suicidal ideation, and drinking motives in underage college drinkers. Addictive Behaviors, 34, 993-999.

Greenfield, T. K., \& Room, R. (1997). Situational norms for drinking and drunkenness: trends in the US adult population, 1979-1990. Addiction, 92, 33-47.

Harford, T. C., Wechsler, H., \& Seibring, M. (2002). Attendance and alcohol use at parties and bars in college: A national survey of current drinkers. Journal of Studies on Alcohol, 63, 726-733.

Kairouz, S., Gliksman, L., Demers, A., \& Adlaf, E. M. (2002). For all these reasons, I do drink: A multilevel analysis of contextual reasons for drinking among Canadian undergraduates. Journal of Studies on Alcohol, 63, 600-608.

Kassel, J. D., Jackson, S. I., \& Unrod, M. (2000). Generalized expectancies for negative mood regulation and problem drinking among college students. Journal of Studies on Alcohol, 61, 332-340.

Klein, H., \& Pittman, D. J. (1990). Social occasions and the perceived appropriateness of consuming different alcoholic beverages. Journal of Studies on Alcohol, $51,59-67$.

Knibbe, R. A., van de Goor, I., \& Drop, M. J. (1993). Contextual influences on young people's drinking rates in public drinking places: An observational study. Addiction Research, 1, 269-278.

Kuntsche, E., Knibbe, R., Gmel, G., \& Engels, R. (2005). Why do young people drink? A review of drinking motives. Clinical Psychology Review, 25, 841-861.

Kuntsche, E., Knibbe, R., Gmel, G., \& Engels, R. (2006a). Who drinks and why? A review of sociodemographic, personality, and contextual issues behind the drinking motives in young people. Addictive Behaviors, 31, 1844-1857.

Kuntsche, E., Knibbe, R., Gmel, G., \& Engels, R. (2006b). Replication and validation of the Drinking Motive Questionnaire Revised (DMQ-R) among adolescents in Switzerland. European Addiction Research, 12, 161-168.

Kuntsche, E., Stewart, S. H., \& Cooper, M. L. (2008). How stable is the motive-alcohol use link? A crossnational validation of the Drinking Motives Questionnaire Revised among adolescents from Switzerland, Canada, and the United States. Journal of Studies on Alcohol and Drugs, 69, 388-396.

Labouvie, E., \& Bates, M. E. (2002). Reasons for alcohol use in young adulthood: Validation of a threedimensional measure. Journal of Studies on Alcohol, 63, 145-155.

Lange, J. E., Devos-Comby, L., Moore, R. S., Daniela, J., \& Homer, K. (2011). Collegiate natural drinking groups: Characteristics, structure, and processes. Addiction Research and Theory, 19, 312-322.

Lo Monaco, G. G., Piermattéo, A., Guimelli, C., \& ErnstVintila, A. (2011). Using the black sheep effect to reveal normative stakes: The example of alcohol drinking contexts. European Journal of Social Psychology, 41, 1-5.

Mayer, R. R., Forster, J. L., Murray, D. M., \& Wagenaar, A. C. (1998). Social settings and situations of 
underage drinking. Journal of Studies on Alcohol, 59, 207-215

Mihic, L., Wells, S., Graham, K., Tremblay, P. F., \& Demers, A. (2009). Situational and respondent-level motives for drinking and alcohol-related aggression: A multilevel analysis of drinking events in a sample of Canadian university students. Addictive Behaviors, 34, 264-269.

Schwarz, N., Bless, H., Strack, F., Klumpp, G., RittenauerSchatka, H., \& Simons, A. (1991). Ease of retrieval as information: Another look at the availability heuristic. Journal of Personality and Social Psychology, 61, 195-202.

Tversky, A., \& Kahneman, D. (1973). Availability: A heuristic for judging frequency and probability. Cognitive Psychology, 42, 207-232. 